\title{
Influence of High-Pressure Nitrogenation on the Structural, Magnetic and Magnetocaloric Properties of $\mathrm{La}_{0.5} \mathrm{Pr}_{0.5} \mathrm{Fe}_{11.4} \mathrm{Si}_{1.6}$
}

\author{
Nai-Kun Sun ${ }^{1} \cdot$ Zeng-Xin Ren $^{1} \cdot$ Jie Guo $^{1} \cdot$ Sheng-Jie Du${ }^{1} \cdot$ Ping-Zhan Si $^{2}$
}

Received: 21 August 2015/Revised: 20 October 2015/Published online: 13 November 2015

(C) The Chinese Society for Metals and Springer-Verlag Berlin Heidelberg 2015

\begin{abstract}
Nitrogenation of $\mathrm{La}_{0.5} \mathrm{Pr}_{0.5} \mathrm{Fe}_{11.4} \mathrm{Si}_{1.6}$ with a particle size of $100-150 \mu \mathrm{m}$ was performed in a high-purity $\mathrm{N}_{2}$ atmosphere of $40 \mathrm{MPa}$. $\mathrm{La}_{0.5} \mathrm{Pr}_{0.5} \mathrm{Fe}_{11.4} \mathrm{Si}_{1.6} \mathrm{~N}_{0.3}$ nitrogenated at $480{ }^{\circ} \mathrm{C}$ exhibits an increase in the Curie temperature $T_{\mathrm{C}}$ from 187 to $195 \mathrm{~K}$. Moreover, for a field change from 0 to $1.5 \mathrm{~T}$, the maximum hysteresis loss at $T_{\mathrm{C}}$ is remarkably reduced from 53 to $3 \mathrm{~J} \mathrm{~kg}^{-1}$ and a large magnetic-entropy change $\Delta S_{\mathrm{m}}$ of over $10 \mathrm{~J} \mathrm{~kg}^{-1} \mathrm{~K}^{-1}$ is maintained. For a $\mathrm{La}_{0.5} \operatorname{Pr}_{0.5}$ $\mathrm{Fe}_{11.4} \mathrm{Si}_{1.6} \mathrm{~N}_{1.2}$ sample, nitrogenated at $550{ }^{\circ} \mathrm{C}$, the XRD pattern clearly exhibits two $1: 13$ phases and, accordingly, the thermal magnetic curves exhibit two transitions, at 210 and at $295 \mathrm{~K}$. The two transitions lead, for a field change of $5 \mathrm{~T}$, to a $\Delta S_{\mathrm{m}}$ larger than $2 \mathrm{~J} \mathrm{~kg}^{-1} \mathrm{~K}^{-1}$ over a large temperature range from 200 to $310 \mathrm{~K}$ with a maximum value of $5.3 \mathrm{~J} \mathrm{~kg}^{-1} \mathrm{~K}^{-1}$ at $225 \mathrm{~K}$. Upon further increase in the nitrogenation temperature to $650{ }^{\circ} \mathrm{C}$, the amount of the nitrogenpoor phase strongly decreases and a large amount of $\alpha-\mathrm{Fe}$ precipitates, resulting in a large reduction in the MCE.
\end{abstract}

KEY WORDS: Metals and alloys; Magnetocaloric effect; Magnetic hysteresis

\section{Introduction}

Nowadays, increasing interest is paid to $\mathrm{La}\left(\mathrm{Fe}_{1-x} \mathrm{Si}_{x}\right)_{13}$ compounds due to their low material costs, non-toxic constituting elements and large magnetocaloric effect (MCE) compared to other room-temperature giant $\mathrm{MCE}$ materials such as $\mathrm{Gd}_{5}\left(\mathrm{Ge}_{1-x} \mathrm{Si}_{x}\right)_{4}$ [1], $\mathrm{MnFeP}_{0.45} \mathrm{As}_{0.55}$ [2] and MnAs-based compounds [3,4]. The large MCE of $\mathrm{La}\left(\mathrm{Fe}_{1-x} \mathrm{Si}_{x}\right)_{13}$ compounds is associated with a temperature-induced paramagnetic-ferromagnetic (PM-FM) transition and with a field-induced itinerant-electron

Available online at http://link.springer.com/journal/40195

Nai-Kun Sun

naikunsun@163.com

1 School of Science, Shenyang Ligong University, Shenyang 110159, China

2 College of Materials Science and Engineering, China Jiliang University, Hangzhou 310018, China metamagnetic (IEM) transition [5]. Both transitions are accompanied by a large volume increase in up to $1.35 \%$ [6], which causes large thermal and magnetic hysteresis and confines the practical use of the materials. Furthermore, the Curie temperature $T_{\mathrm{C}}$ of the $\mathrm{La}\left(\mathrm{Fe}_{1-x} \mathrm{Si}_{x}\right)_{13}$ compounds is about $200 \mathrm{~K}$. As a consequence, much effort has been made to reduce the hysteresis and to increase $T_{\mathrm{C}}$. In the $\mathrm{La}_{0.5} \mathrm{Pr}_{0.5} \mathrm{Fe}_{11.5} \mathrm{Si}_{1.5} \mathrm{C}_{0.3}$ compound, $T_{\mathrm{C}}$ has increased to $211 \mathrm{~K}$, and meanwhile, a large MCE is maintained [7]. However, a large hysteresis loss of $23 \mathrm{~J} \mathrm{~kg}^{-1} \mathrm{~K}^{-1}$ still remains. The introduction of interstitial hydrogen atoms increases $T_{\mathrm{C}}$ to room temperature without seriously reducing the MCE. However, the chemical stability of the hydrides is a problem. Addition of boron has increased the $T_{\mathrm{C}}$ of $\mathrm{LaFe}_{11.5} \mathrm{Si}_{1.5}$ from 183 to $230 \mathrm{~K}$, but unfortunately, the MCE is largely reduced because the nature of the magnetic transition has been changed from first order to second order [8].

The intrinsic magnetic properties, especially the magnetic anisotropy, of many rare earth transition metal compounds, such as $\mathrm{R}_{2} \mathrm{Fe}_{17}$ and $\mathrm{RFe}_{11} \mathrm{Ti}$ ( $\mathrm{R}$ is the rare earth 
element), have been found to be improved dramatically due to the introduction of interstitial nitrogen $[9,10]$. Nitrogenation also has strong effects on the cubic $\mathrm{NaZn}_{13}$-type $\mathrm{La}(\mathrm{Fe}, \mathrm{Co})_{13}$-based compounds, including a large lattice expansion and increase in $T_{\mathrm{C}}$ and the spontaneous magnetization [11-13]. So far, only a few studies have been focused on the influence of interstitial nitrogen on the MCE of $\mathrm{La}\left(\mathrm{Fe}_{1-x} \mathrm{Si}_{x}\right)_{13}$-based compounds. Insertion of 1.3 nitrogen atoms per $\mathrm{LaFe}_{11.7} \mathrm{Si}_{1.3}$ formula increases the lattice constant from 11.467 to $11.733 \AA$ and the $T_{\mathrm{C}}$ from 190 to $230 \mathrm{~K}$. However, the MCE is greatly reduced from 28 to $3.5 \mathrm{~J} \mathrm{~kg}^{-1} \mathrm{~K}^{-1}$ when the field changes from 0 to $5 \mathrm{~T}$ because the nature of the magnetic phase transition has changed to second order [14]. In general, nitrogenation is carried out at low $\mathrm{N}_{2}$ pressure and, in order to make the gas-solid reaction proceed more completely, the material is crushed into the particles smaller than $45 \mu \mathrm{m}$ for increasing the sample surface. However, when bulk material is broken into small particles, the MCE can be greatly reduced [15, 16]. Higher $\mathrm{N}_{2}$ pressure is expected to increase the homogenization of nitrogenation. In the present work, nitrogenation of $\mathrm{La}_{0.5} \mathrm{Pr}_{0.5} \mathrm{Fe}_{11.4} \mathrm{Si}_{1.6}$ with a particle size of $100-150 \mu \mathrm{m}$ has been performed in a high-purity $\mathrm{N}_{2}$ atmosphere of $40 \mathrm{MPa}$. The influence of high-pressure nitrogenation at different temperatures on the structure, magnetic and MCE properties of $\mathrm{La}_{0.5} \mathrm{Pr}_{0.5} \mathrm{Fe}_{11.4} \mathrm{Si}_{1.6}$ has been systematically investigated.

\section{Experimental}

The parent compound $\mathrm{La}_{0.5} \mathrm{Pr}_{0.5} \mathrm{Fe}_{11.4} \mathrm{Si}_{1.6}$ was synthesized in an induction furnace. The starting materials are $\mathrm{Pr}, \mathrm{La}$, $\mathrm{Fe}$ and $\mathrm{Fe}$ with commercial purity of $99,99,99$ and $99.99 \%$, respectively, which were mixed and the obtained ingots were annealed at $1050{ }^{\circ} \mathrm{C}$ for 10 days. The samples were then ground to particles of $100-150 \mu \mathrm{m}$ and nitrogenated by using a self-made furnace in a high-purity $\mathrm{N}_{2}$ atmosphere of $40 \mathrm{MPa}$ at 480,550 and $650{ }^{\circ} \mathrm{C}$. The $\mathrm{N}$ contents in the $\mathrm{La}_{0.5} \mathrm{Pr}_{0.5} \mathrm{Fe}_{11.4} \mathrm{Si}_{1.6} \mathrm{~N}_{x}$ compounds were determined from the weight difference before and after nitrogenation to be $x=0.3,1.2$ and 2.1, respectively.

X-ray diffraction (XRD) was performed using $\mathrm{Cu} K_{\alpha}$ radiation with a Rigaku $d / \mathrm{Max}-\gamma \mathrm{A}$ diffractometer. The magnetic properties were measured using a superconducting quantum interference device (SQUID) magnetometer and a vibrating-sample magnetometer (Lakeshore 7407) $(100 \mathrm{~K} \leq T \leq 400 \mathrm{~K}, 0 \mathrm{~T} \leq B \leq 5 \mathrm{~T})$. The magnetic-entropy change $\Delta S_{\mathrm{m}}$ was derived from M-B curves, measured at various temperatures close to the phase transition.

\section{Results and Discussion}

Figure 1 shows the XRD patterns of $\mathrm{La}_{0.5} \mathrm{Pr}_{0.5} \mathrm{Fe}_{11.4} \mathrm{Si}_{1.6} \mathrm{~N}_{x}$ $(x=0,0.3,1.2,2.1)$. The results indicate that the prepared $\mathrm{La}_{0.5} \mathrm{Pr}_{0.5} \mathrm{Fe}_{11.4} \mathrm{Si}_{1.6}$ parent bulk compound possesses a cubic $\mathrm{NaZn}_{13}$-type structure with a small amount of $\alpha-\mathrm{Fe}$ as impurity phase. For $\mathrm{La}_{0.5} \mathrm{Pr}_{0.5} \mathrm{Fe}_{11.4} \mathrm{Si}_{1.6} \mathrm{~N}_{0.3}$ nitrogenated at $480{ }^{\circ} \mathrm{C}$, the (531), (422) and (420) reflections of the $\mathrm{NaZn}_{13}$-type main phase begin to separate and, for $\mathrm{La}_{0.5} \mathrm{Pr}_{0.5} \mathrm{Fe}_{11.4} \mathrm{Si}_{1.6} \mathrm{~N}_{1.2}$ nitrogenated at $550{ }^{\circ} \mathrm{C}$, the XRD pattern clearly exhibits two $1: 13$ phases, indicating a twophase mixture of nitrogen-poor and nitrogen-rich phases. It can be clearly seen that the reflections of the cubic $\mathrm{NaZn}_{13^{-}}$ type structure for the nitrogen-rich phase shift to lower angles, indicating larger lattice parameters and higher contents of $\mathrm{N}$. In accordance with the two phases with different $\mathrm{N}$ contents, the thermal magnetization curves of the $\mathrm{La}_{0.5} \mathrm{Pr}_{0.5} \mathrm{Fe}_{11.4} \mathrm{Si}_{1.6} \mathrm{~N}_{1.2}$ sample exhibit two transitions at 210 and at $295 \mathrm{~K}$ (as shown in Fig. 3a). The inhomogeneity of nitrogenation for the two samples can be ascribed to the comparative low nitrogenation temperature and the large nitrogenated particle size of $100-150 \mu \mathrm{m}$ in the present nitrogenation study. It has been previously reported that the minimum nitrogenation temperature for $\mathrm{LaFe}_{13-x} \mathrm{Si}_{x}$ compounds is $650{ }^{\circ} \mathrm{C}$ under an ambient pressure [13]. The present study suggests that, despite the high pressure of $40 \mathrm{MPa}$, the nitrogenation temperature of $550{ }^{\circ} \mathrm{C}$ is still too low to obtain complete and homogeneous nitrogenation. In previous experiments, the

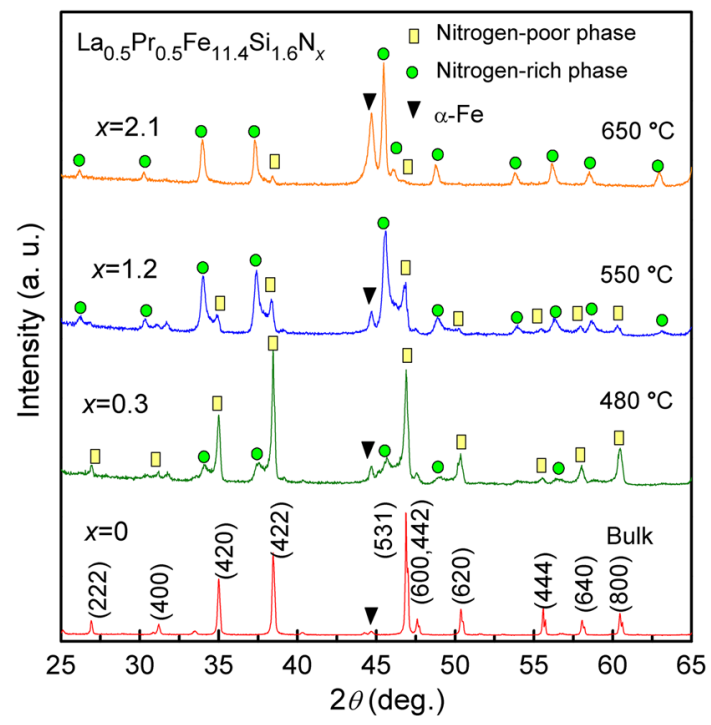

Fig. 1 XRD patterns of $\mathrm{La}_{0.5} \mathrm{Pr}_{0.5} \mathrm{Fe}_{11.4} \mathrm{Si}_{1.6} \mathrm{~N}_{x}(x=0,0.3,1.2$ and 2.1) compounds nitrogenated at different temperatures 
nitrogenated particles were smaller than $45 \mu \mathrm{m}[13]$ and it is understandable that, at larger particle size, it is more difficult to achieve a homogeneous distribution of the nitrogen atoms in the material. With further increase in the nitrogenation temperature to $650{ }^{\circ} \mathrm{C}$, the amount of the nitrogen-rich phase further increases, while the amount of the nitrogen-poor phase strongly decreases. It is worthwhile noting that a large amount of $\alpha-\mathrm{Fe}$ precipitates. In the previous work [17], a similar precipitation of large amounts of Mo and $\alpha-\mathrm{Fe}$ from the main phase has been observed in $\mathrm{SmFe}_{10} \mathrm{Mo}_{2}$ with increase in the nitrogenation pressure to $40 \mathrm{MPa}$.

The temperature dependence of the magnetization of $\mathrm{La}_{0.5} \mathrm{Pr}_{0.5} \mathrm{Fe}_{11.4} \mathrm{Si}_{1.6} \mathrm{~N}_{x}$ compounds with $x=0.0$ and 0.3 was measured in a field of $0.05 \mathrm{~T}$ during the warming process. For comparison, the parent compound $\mathrm{La}_{0.5} \mathrm{Pr}_{0.5}$ $\mathrm{Fe}_{11.4} \mathrm{Si}_{1.6}$ with the same particle size of $100-150 \mathrm{~nm}$ was measured. As shown in Fig. 2, with increasing temperature, a first-order magnetic phase transition from the FM to PM state takes place at $T_{\mathrm{C}}$ of $186 \mathrm{~K}$ and $195 \mathrm{~K}$ for $x=0.0$ and 0.3 , respectively. $T_{\mathrm{C}}$ has been defined as the temperature corresponding to the minimum in the temperature dependence of the first derivative of the magnetization $(\mathrm{d} M / \mathrm{d} T)$. Previously, it has been observed that the introductions of the interstitial hydrogen, boron or carbon atoms also cause the Curie temperature to increase due to the variation of $\mathrm{Fe}-\mathrm{Fe}$ bond length and both the lattice parameter $a$ and $T_{\mathrm{C}}$ are found to increase linearly with the interstitial-atom contents $[13,18]$. It has been reported that the $\mathrm{Fe}-\mathrm{Fe}$ interaction is a key factor that influences the magnetic properties of Fe-rich rare earth iron compounds and the Curie temperature strongly depends on the $\mathrm{Fe}-\mathrm{Fe}$ distance [19]. Neutron diffraction has shown that the $\mathrm{N}$ atoms in $\mathrm{LaFe}_{11} \mathrm{Al}_{2}$ nitrides occupy exclusively the $24 \mathrm{~d}$ interstitial site [20]. Thus, the increase in $T_{\mathrm{C}}$ in the present

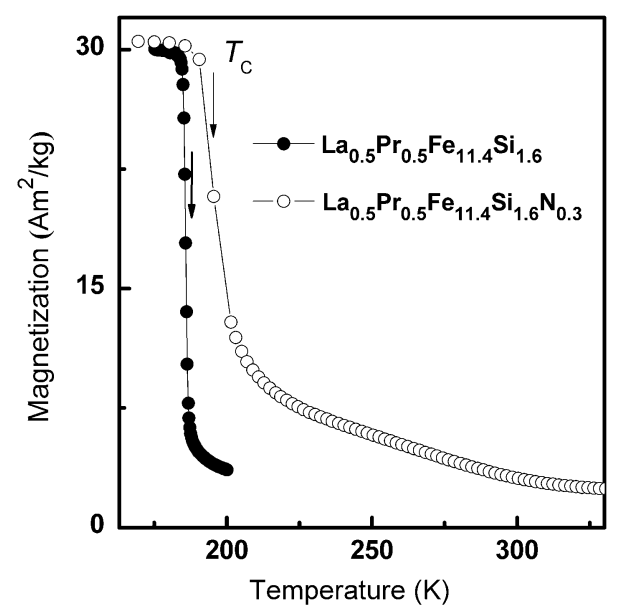

Fig. 2 Temperature dependence of the magnetization at $0.05 \mathrm{~T}$ of $\mathrm{La}_{0.5} \mathrm{Pr}_{0.5} \mathrm{Fe}_{11.4} \mathrm{Si}_{1.6} \mathrm{~N}_{x}$ compounds with $x=0$ and 0.3
$\mathrm{La}_{0.5} \mathrm{Pr}_{0.5} \mathrm{Fe}_{11.4} \mathrm{Si}_{1.6} \mathrm{~N}_{x}$ can be attributed to variation of the $\mathrm{Fe}-\mathrm{Fe}$ bond length caused by the interstitial nitrogen atoms.

The temperature dependences of the magnetization of $\mathrm{La}_{0.5} \mathrm{Pr}_{0.5} \mathrm{Fe}_{11.4} \mathrm{Si}_{1.6} \mathrm{~N}_{1.2}$ and $\mathrm{La}_{0.5} \mathrm{Pr}_{0.5} \mathrm{Fe}_{11.4} \mathrm{Si}_{1.6} \mathrm{~N}_{2.1}$, measured in a zero-field-cooled process (ZFC) and field-cooled process (FC), are shown in Fig. 3. The magnetization of $\mathrm{La}_{0.5} \mathrm{Pr}_{0.5} \mathrm{Fe}_{11.4} \mathrm{Si}_{1.6} \mathrm{~N}_{1.2}$ begins to decrease gradually above $200 \mathrm{~K}$, and there are two minima in the $\mathrm{d} M / \mathrm{d} T$ curves, suggesting that, in accordance with the two 1:13 phases with different nitrogen contents, two transitions occur at about 210 and $295 \mathrm{~K}$ (as shown in the inset of Fig. 3a). This result is in accordance with the XRD results in Fig. 1. A previous study [13] indicated that $T_{\mathrm{C}}$ of $\mathrm{La}(\mathrm{Fe}, \mathrm{Si})_{13}$ compounds can be increased to the room temperature upon nitrogenation. The thermal magnetic curves of $\mathrm{La}_{0.5} \mathrm{Pr}_{0.5}$ $\mathrm{Fe}_{11.4} \mathrm{Si}_{1.6} \mathrm{~N}_{2.1}$ show almost the same behavior as $\mathrm{La}_{0.5}$ $\mathrm{Pr}_{0.5} \mathrm{Fe}_{11.4} \mathrm{Si}_{1.6} \mathrm{~N}_{1.2}$ with two magnetic transitions at 200 and $290 \mathrm{~K}$ (as shown in the inset of Fig. 3b). The lower $T_{\mathrm{C}}$ can be ascribed to the larger amount of precipitation of $\alpha-$ $\mathrm{Fe}$, which leads to a change of the composition of the main phase. It has been reported that $T_{\mathrm{C}}$ of $\mathrm{La}(\mathrm{Fe}, \mathrm{Si})_{13}$ hydrides is very sensitive to the hydrogen content [21], and thus, inhomogeneous distribution of the nitrogen atoms can lead to the quite different transition temperatures of the present $\mathrm{La}_{0.5} \mathrm{Pr}_{0.5} \mathrm{Fe}_{11.4} \mathrm{Si}_{1.6}$ nitrides.

To explore the effect of high-pressure nitrogenation on the field-induced IEM transition and especially on the hysteresis loss, the magnetic field dependence of the magnetization $(M(B))$ was measured. As shown in Fig. 4a, $\mathrm{b}$, at temperatures close to $T_{\mathrm{C}}$, after an initial linear increase at low fields, which reveals that the compound is in the paramagnetic state, the magnetization of

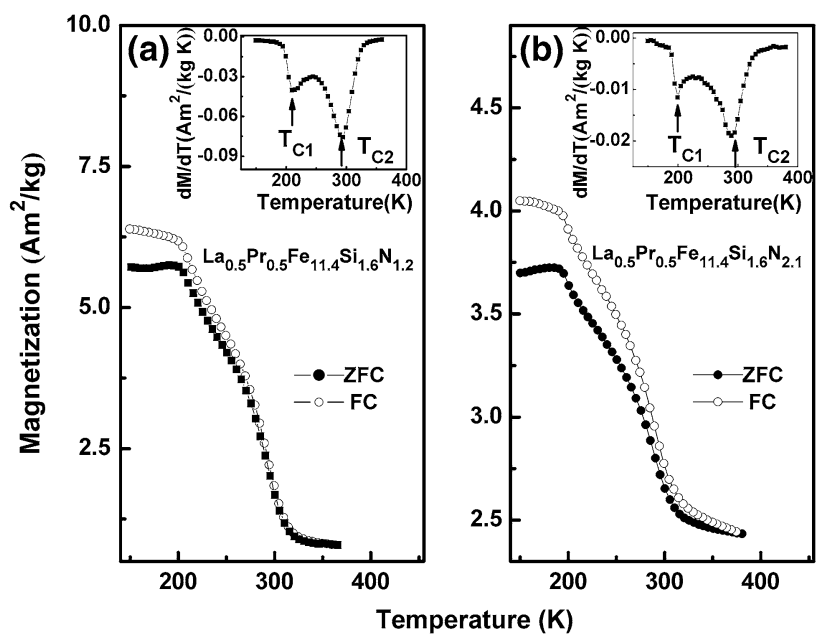

Fig. 3 Temperature dependence of the magnetization at $0.05 \mathrm{~T}$ of $\mathrm{La}_{0.5} \mathrm{Pr}_{0.5} \mathrm{Fe}_{11.4} \mathrm{Si}_{1.6} \mathrm{~N}_{x}$ compounds with $x=1.2$ a and $2.1 \mathbf{b}$, where the insets show the first derivative of the magnetization $(\mathrm{d} M / \mathrm{d} T)$ as a function of temperature 


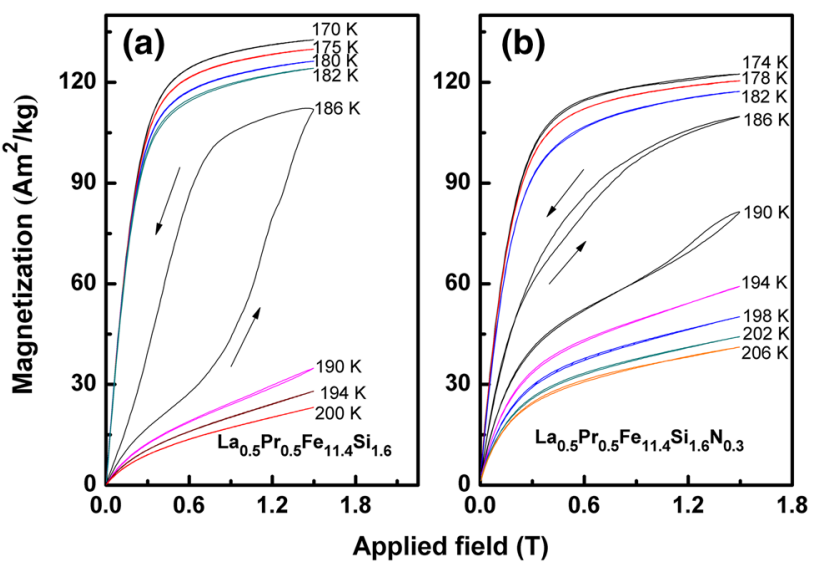

Fig. 4 Field dependence of the magnetization of $\mathrm{La}_{0.5} \operatorname{Pr}_{0.5} \mathrm{Fe}_{11.4-}$ $\mathrm{Si}_{1.6} \mathrm{~N}_{x}$ compounds at temperatures near $T_{\mathrm{C}}$ for $x=0 \mathbf{a}$ and $x=0.3 \mathbf{b}$

$\mathrm{La}_{0.5} \mathrm{Pr}_{0.5} \mathrm{Fe}_{11.4} \mathrm{Si}_{1.6}$ shows an abrupt increase, indicating a field-induced first-order IEM transition. In sharp contrast with this, however for $\mathrm{La}_{0.5} \mathrm{Pr}_{0.5} \mathrm{Fe}_{11.4} \mathrm{Si}_{1.6} \mathrm{~N}_{0.3}$, no clear inflection point is observed in the $M(B)$ curves showing the weakness of the first-order transition. It is clearly seen that the magnetic hysteresis, defined as the enclosed area in the field cycle shown in Fig. 4, remarkably decreases upon the introduction of nitrogen. The maximum hysteresis loss is $53 \mathrm{~J} \mathrm{~kg}^{-1}$ for the bulk parent compound and $3 \mathrm{~J} \mathrm{~kg}^{-1}$ for $x=0.3$, showing an enormous decrease in the hysteresis loss after high-pressure nitrogenation. When the average particle size of the fragments is below $100 \mu \mathrm{m}$, it exhibits a lower operating field for the magnetic transition and smaller hysteresis loss due to the reduction in internal strain $[15,16]$. Also, some extrinsic factors, such as sample geometry and the conditions for heat transfer, can influence the magnetic hysteresis [22, 23]. In addition, during the first-order structural transition, the internal strain can influence the hysteresis by confining the volume expansion $[6,24]$. Recently, it has been reported that in plate-shaped $\mathrm{La}_{0.5} \mathrm{Pr}_{0.5} \mathrm{Fe}_{11.4} \mathrm{Si}_{1.6}$ hydrides sintered in high-pressure $\mathrm{H}_{2}$ atmosphere, hysteresis is almost absent due to the existence of the micropores and a large size distribution ranging from several micrometers to about $100 \mu \mathrm{m}$ [25]. As stated above, the sizes of both the parent alloy and the nitride particles are $100-150 \mu \mathrm{m}$, and the physical mechanism of the hysteresis reduction in $\mathrm{La}_{0.5} \mathrm{Pr}_{0.5} \mathrm{Fe}_{11.4} \mathrm{Si}_{1.6}$ nitrides can be ascribed to some intrinsic factors. The influence of hydrogenation on the magnetism of $\mathrm{La}_{0.5} \mathrm{Pr}_{0.5} \mathrm{Fe}_{11.4} \mathrm{Si}_{1.6}$ has been interpreted by the renormalization effect of spin fluctuations based on the Landau-Ginzburg theory [19]. Similarly, in the present $\mathrm{La}_{0.5} \mathrm{Pr}_{0.5} \mathrm{Fe}_{11.4} \mathrm{Si}_{1.6} \mathrm{~N}_{x}$ compounds, the interstitial nitrogen may modify the spin fluctuations at $T_{\mathrm{C}}$ and lower the energy barrier separating the PM and FM state, leading to considerable improvement of the magnetic hysteresis behavior.

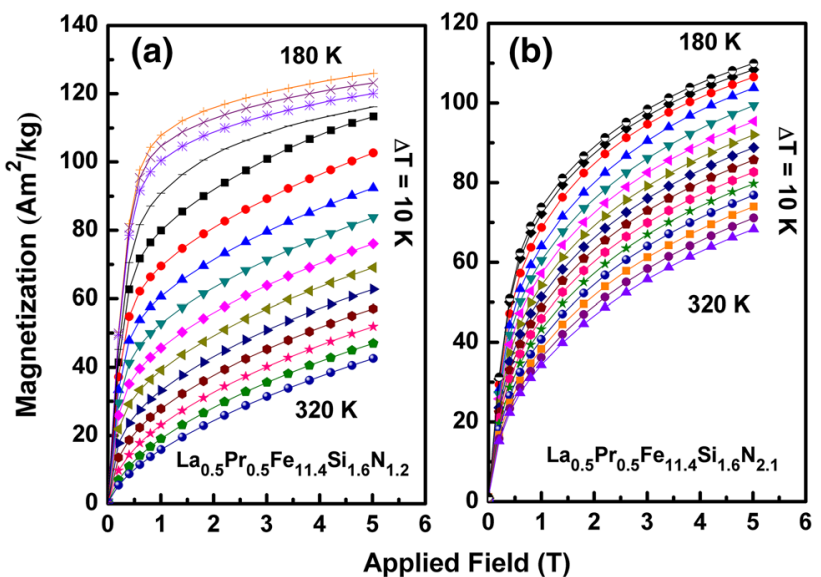

Fig. 5 Field dependence of the magnetization of $\mathrm{La}_{0.5} \mathrm{Pr}_{0.5} \mathrm{Fe}_{11.4-}$ $\mathrm{Si}_{1.6} \mathrm{~N}_{x}$ compounds at temperatures near $T_{\mathrm{C}}$ for $x=1.2 \mathrm{a}$ and $x=2.1$ b

As shown in Fig. 5a, b, the magnetic isotherms of $\mathrm{La}_{0.5} \mathrm{Pr}_{0.5} \mathrm{Fe}_{11.4} \mathrm{Si}_{1.6} \mathrm{~N}_{1.2}$ and $\mathrm{La}_{0.5} \mathrm{Pr}_{0.5} \mathrm{Fe}_{11.4} \mathrm{Si}_{1.6} \mathrm{~N}_{2.1}$ show second-order-transition characteristics. The magnetic fieldinduced IEM transition near the Curie temperature is not observed. These results indicate that the first-order transition has become much weaker after nitrogenation.

The magnetic-entropy change $\Delta S_{\mathrm{m}}(T, B)$ for a magnetic field change is given by the Maxwell relationship: $\Delta S_{\mathrm{m}}(T, B)=S(T, B)-S(T, 0)=\int_{0}^{B}\left(\frac{\partial M}{\partial T}\right)_{B} \mathrm{~d} B . \quad$ Figure 6a displays the temperature dependence of $\Delta S_{\mathrm{m}}$ of $\mathrm{La}_{0.5}$ $\mathrm{Pr}_{0.5} \mathrm{Fe}_{11.4} \mathrm{Si}_{1.6}$ and $\mathrm{La}_{0.5} \mathrm{Pr}_{0.5} \mathrm{Fe}_{11.4} \mathrm{Si}_{1.6} \mathrm{~N}_{0.3}$ for a magnetic field change from 0 to $1.5 \mathrm{~T}$. The maximal $\Delta S_{\mathrm{m}}$ for the parent compound $\mathrm{La}_{0.5} \mathrm{Pr}_{0.5} \mathrm{Fe}_{11.4} \mathrm{Si}_{1.6}$ with particle size $100-150 \mu \mathrm{m}$ is $23 \mathrm{~J} \mathrm{~kg}^{-1} \mathrm{~K}^{-1}$ at $184 \mathrm{~K}$. The maximal $\Delta S_{\mathrm{m}}$ of $\mathrm{La}_{0.5} \mathrm{Pr}_{0.5} \mathrm{Fe}_{11.4} \mathrm{Si}_{1.6} \mathrm{~N}_{0.3}$ has decreased remarkably to $10.3 \mathrm{~J} \mathrm{~kg}^{-1} \mathrm{~K}^{-1}$ at $190 \mathrm{~K}$. The shift of the peak

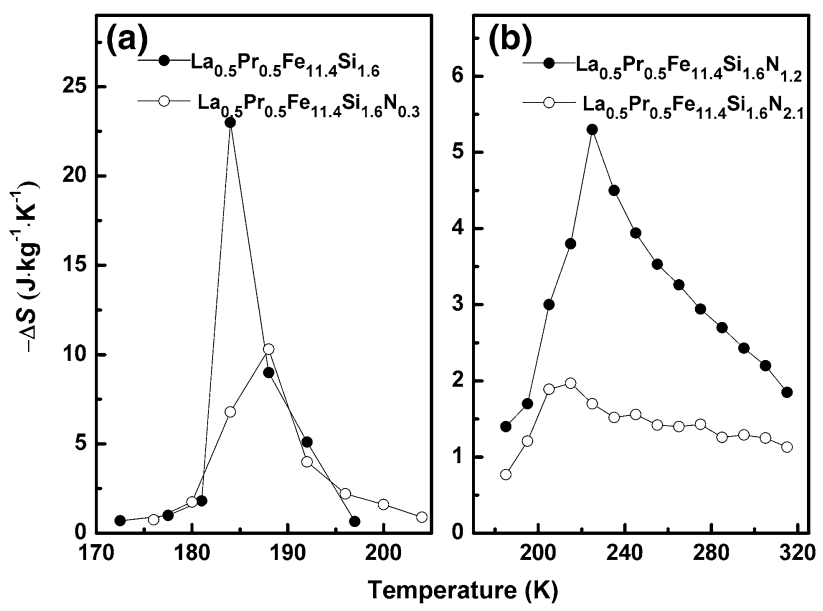

Fig. 6 Magnetic-entropy changes of $\mathrm{La}_{0.5} \mathrm{Pr}_{0.5} \mathrm{Fe}_{11.4} \mathrm{Si}_{1.6} \mathrm{~N}_{\mathrm{x}}$ compounds at an external field change from 0 to $1.5 \mathrm{~T}$ for $x=0$ and $x=0.3 \mathbf{a}$ and from 0 to $5 \mathrm{~T}$ for $x=1.2$ and $x=2.1 \mathbf{b}$ 
temperature to higher temperatures and the remarkable decrease in the maximal $\Delta S_{\mathrm{m}}$ are ascribed to the higher $T_{\mathrm{C}}$ and the less pronounced first-order transition caused by nitrogenation. As stated above, $\mathrm{La}_{0.5} \mathrm{Pr}_{0.5} \mathrm{Fe}_{11.4} \mathrm{Si}_{1.6} \mathrm{~N}_{1.2}$ which consists of two 1:13 phases exhibits two transitions at 210 and at $295 \mathrm{~K}$. The two transitions lead to a $\Delta S_{\mathrm{m}}$ larger than $2 \mathrm{~J} \mathrm{~kg}^{-1} \mathrm{~K}^{-1}$ over the large temperature range from 200 to $310 \mathrm{~K}$ with a maximum $\Delta S_{\mathrm{m}}$ value of $5.3 \mathrm{~J} \mathrm{~kg}^{-1} \mathrm{~K}^{-1}$ for a field change of $5 \mathrm{~T}$ at $225 \mathrm{~K}$ (as shown in Fig. 6b). For $\mathrm{La}_{0.5} \mathrm{Pr}_{0.5} \mathrm{Fe}_{11.4} \mathrm{Si}_{1.6} \mathrm{~N}_{2.1}$, the MCE has much decreased to a maximum $\Delta S_{\mathrm{m}}$ of $2.0 \mathrm{~J} \mathrm{~kg}^{-1} \mathrm{~K}^{-1}$ for a field change of $5 \mathrm{~T}$ at $215 \mathrm{~K}$ which is due to the fact that a large amount of $\alpha-\mathrm{Fe}$ has precipitated upon increasing the nitrogenation temperature to $650{ }^{\circ} \mathrm{C}$.

\section{Conclusions}

$\mathrm{La}_{0.5} \mathrm{Pr}_{0.5} \mathrm{Fe}_{11.4} \mathrm{Si}_{1.6}$ nitrides with a particle size of 100-150 $\mu \mathrm{m}$ were prepared by using a self-made furnace in a high-purity $\mathrm{N}_{2}$ atmosphere of $40 \mathrm{MPa}$. Curie temperature $T_{\mathrm{C}}$ of $\mathrm{La}_{0.5} \mathrm{Pr}_{0.5} \mathrm{Fe}_{11.4} \mathrm{Si}_{1.6} \mathrm{~N}_{0.3}$ increases from $187 \mathrm{~K}$ for the parent bulk compound to $195 \mathrm{~K}$. Moreover, the maximum hysteresis loss for a field change from 0 to $1.5 \mathrm{~T}$ at $T_{\mathrm{C}}$ is considerably reduced from 53 to $3 \mathrm{~J} \mathrm{~kg}^{-1}$ and a large $\Delta S_{\mathrm{m}}$ of more than $10 \mathrm{~J} \mathrm{~kg}^{-1} \mathrm{~K}^{-1}$ is maintained. The XRD pattern of $\mathrm{La}_{0.5} \mathrm{Pr}_{0.5} \mathrm{Fe}_{11.4} \mathrm{Si}_{1.6} \mathrm{~N}_{1.2}$ exhibits two $1: 13$ phases and, accordingly, the magnetization exhibits two transitions at 210 and at $295 \mathrm{~K}$. The two transitions lead, for a field change from 0 to $5 \mathrm{~T}$, to a $\Delta S_{\mathrm{m}}$ value larger than $2 \mathrm{~J} \mathrm{~kg}^{-1} \mathrm{~K}^{-1}$ over a large temperature range from 200 to $310 \mathrm{~K}$ with a maximum $\Delta S_{\mathrm{m}}$ value of $5.3 \mathrm{~J} \mathrm{~kg}^{-1} \mathrm{~K}^{-1}$ at $225 \mathrm{~K}$. The present nitrogenation study may be useful for the practical application of the $\mathrm{La}(\mathrm{Fe}, \mathrm{Si})_{13}$-based compounds.

Acknowledgments This work was financially supported by the Liaoning Provincial Natural Science Foundation (No. 2013020105) and the Shenyang Science and Technology Foundation (No. F13-3161-39).

\section{References}

[1] V.K. Pecharsky, K.A. Gschneidner Jr, Phys. Rev. Lett. 78, 4494 (1997)
[2] O. Tegus, E. Brück, K.H.J. Buschow, F.R. de Boer, Nature 415, 150 (2002)

[3] H. Wada, Y. Tanabe, Appl. Phys. Lett. 79, 3302 (2001)

[4] N.K. Sun, S.N. Xu, Y.B. Gao, T.B. Ji, Y.B. Li, Phys. B 406, $2731(2011)$

[5] F.X. Hu, B.G. Shen, J.R. Sun, Z.H. Cheng, G.H. Rao, X.X. Zhang, Appl. Phys. Lett. 78, 3675 (2001)

[6] J. Lyubina, R. Schäfer, N. Martin, L. Schultz, O. Gutfleisch, Adv. Mater. 22, 3735 (2010)

[7] J. Shen, B. Gao, H.W. Zhang, F.X. Hu, Y.X. Li, J.R. Sun, B.G. Shen, Appl. Phys. Lett. 91, 142504 (2007)

[8] H. Zhang, Y. Long, Q. Cao, Y. Mudryk, M. Zou, K.A. Gschneidner Jr, V.K. Pecharsky, J. Magn. Magn. Mater. 322, 1710 (2010)

[9] J.M.D. Coey, H. Sun, J. Magn. Magn. Mater. 87, L251 (1990)

[10] Y.Z. Wang, G.C. Hadjipanayis, J. Appl. Phys. 70, 6009 (1991)

[11] M.Q. Huang, Y. Zheng, K. Miller, J. Elbicki, W.E. Wallace, S.G. Sankar, IEEE Trans. Magn. 28, 2859 (1992)

[12] J.P. Liu, N. Tang, F.R. de Boer, P.F. de Châtel, K.H.J. Buschow, J. Magn. Magn. Mater. 140-144, 1035 (1995)

[13] Z.X. Tang, X.H. Deng, G.C. Hadjipanayis, V. Papaefthymiou, D.J. Sellmyer, IEEE Trans. Magn. 29, 2839 (1993)

[14] M. Balli, M. Rosca, D. Fruchart, D. Gignoux, J. Magn. Magn. Mater. 321, 123 (2009)

[15] J.D. Moore, G.K. Perkins, Y. Bugoslavsky, M.K. Chattopadhyay, S.B. Roy, P. Chaddah, V.K. Pecharsky, K.A. Gschneidner Jr, L.F. Cohen, Appl. Phys. Lett. 88, 072501 (2006)

[16] F.X. Hu, L. Chen, J. Wang, L.F. Bao, J.R. Sun, B.G. Shen, Appl. Phys. Lett. 100, 072403 (2012)

[17] N.K. Sun, J. Guo, S.J. Du, S.N. Xu, P.Z. Si, J.J. Liu, Acta Metall. Sin. (Engl. Lett.) 28, 781 (2015)

[18] L. Jia, J.R. Sun, J. Shen, B. Gao, T.Y. Zhao, H.W. Zhang, F.X. Hu, B.G. Shen, J. Alloys Compd. 509, 5804 (2011)

[19] J.L. Zhao, J. Shen, F.X. Hu, Y.X. Li, J.J. Sun, B.G. Shen, J. Appl. Phys. 107, 113911 (2010)

[20] O. Moze, W. Kockelmann, J.P. Liu, F.R. de Boer, K.H.J. Buschow, J. Magn. Magn. Mater. 195, 391 (1999)

[21] H. Zhang, Y. Long, E. Niu, X.P. Shao, J. Shen, F.X. Hu, J.R. Sun, B.G. Shen, J. Appl. Phys. 113, 17A911 (2013)

[22] J.D. Moore, K. Morrison, K.G. Sandeman, M. Katter, L.F. Cohen, Appl. Phys. Lett. 95, 252504 (2009)

[23] J.H. Huang, N.K. Sun, C.L. Liu, Y.M. Ge, T. Zhang, F. Liu, P.Z. Si, Acta Metall. Sin. (Engl. Lett.) 27, 27 (2014)

[24] H. Zhang, Y.J. Sun, E. Niu, F.X. Hu, J.R. Sun, B.G. Shen, Appl. Phys. Lett. 104, 062407 (2014)

[25] N.K. Sun, J. Guo, X.G. Zhao, P.Z. Si, J.H. Huang, Z.D. Zhang, Appl. Phys. Lett. 106, 092401 (2015) 